\title{
O diálogo inTERCultural PELO PARATEXTo: Notas do tradutor Pasquale Aniel Jannini
}

\section{DaYANA LOVERro*}

RESUMO: Pasquale Aniel Jannini foi um tradutor, ensaísta e professor universitário italiano, tendo atuado principalmente na Universidade La Sapienza de Roma. Era francesista por formação e desenvolvia pesquisas em diversas vertentes acadêmicas. Dentre elas, dedicava-se aos estudos literários em língua portuguesa, do Brasil e de Portugal, e à tradução. Traduziu do português ao italiano alguns textos e obras de escritores como João Guimarães Rosa e Vinicius de Moraes. A partir das notas de rodapé de Orfeo Negro, tradução em italiano da obra Orfeu da Conceição, de Vinicius de Moraes, este artigo busca observar - através do paratexto - de que forma ocorrem determinados diálogos interculturais expressos entre os textos de partida e de chegada.

PALAVRAS-CHAVE: Diálogos Interculturais; Literatura Comparada; Tradução; Italiano; Vinicius de Moraes; Orfeu da Conceição; Orfeo Negro

ABSTRACT: Pasquale Aniel Jannini fu un traduttore, saggista e professore universitario italiano che lavorò soprattutto all'Università La Sapienza di Roma. Era di formazione francesista e sviluppava ricerche in diverse aree accademiche, tra le quali gli studi letterari in lingua portoghese del Portogallo e del Brasile e la traduzione. Tradusse alcuni testi e opere di scrittori come João Guimarães Rosa e Vinicius de Moraes. Partendo dalle note di Orfeo Negro, traduzione in

* Universidade de São Paulo, São Paulo (Brasil) - dayanaloverro@gmail.com

Processo n.2013/20971-0 Fundação de Amparo à Pesquisa do Estado de São Paulo (FAPESP)

DOI: http://dx.doi.org/10.11606/issn.2238-8281.v0i33p61-68 
italiano dell'opera Orfeu da Conceição, di Vinicius de Moraes, questo articolo cerca di osservare - attraverso il paratesto - come avvengono determinati dialoghi interculturali tra i testi di partenza e quelli d'arrivo.

PAROLE CHIAVE: Dialoghi interculturali; Letteratura comparata; Traduzione; Italiano; Vinicius de Moraes; Orfeu da Conceição; Orfeo Negro

ABSTRACT: Pasquale Aniel Jannini was a translator, essayist and Italian university professor and has worked mainly at La Sapienza University of Rome. He was francesist by training and has developed research in various academic aspects. Among them, he devoted himself to literary studies in Portuguese from both Brazil and Portugal, and translation. Jannini translated to Italian some texts and works of Brazilian writers as João Guimarães Rosa and Vinicius de Moraes. From Orfeo Negro's footnotes, Italian translation of the Orfeu da Conceição, from Vinicius de Moraes, this article seeks to observe - through paratext - how certain intercultural dialogue expressed between the starting and target texts occurs.

KEYWORDS: Intercultural Dialogs; Compared Literature; Translation; Italian; Vinicius de Moraes; Orfeu da Conceição; Orfeo Negro 


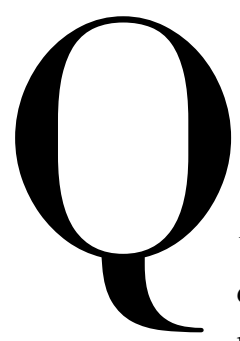

uando um livro é "consumido" - seja no ato de sua aquisição, seja pelo desenvolvimento de sua leitura - por vezes a relação do leitor com suas partes constituintes ocorre de modo tão integrado, prático e espontâneo que as funções, especificidades e os critérios de apresentação de tais elementos de composição passam despercebidos para a maioria dos consumidores finais da obra.

Comumente, a capa produz a primeira impressão, é o que se apresenta no primeiro contato do leitor com um livro. Sabe-se que é importante até mesmo a ponto de influenciar a escolha da leitura e a decisão de compra. A partir dessa importância, o mercado editorial conta com profissionais que lidam especificamente com esse aspecto da produção livreira. No entanto, há ainda outros aspectos que recebem atenção profissional particular para que um livro se constitua como produto final na cadeia editorial. O corpo de texto deve alinhar-se e interligar-se harmonicamente às demais partes integrantes da publicação, como a contracapa, a lombada, as orelhas, o título, a epígrafe, a dedicatória, o índice, o prefácio, as citações, o posfácio, o glossário, a bibliografia, as ilustrações e as notas de rodapé, por exemplo.

Esses itens, denominados “paratextos” (GENETTE, 2009), ao funcionarem em consonância, circundam e demarcam os limites textuais do livro, designando-o como obra e inserindo-o em um novo status comunicativo. Tais estruturas indicam caminhos para acessar os dados do texto, gerando comportamentos no leitor para a extração de informações na leitura. $\mathrm{O}$ termo paratexto 
foi cunhado em 1989, por Gérard Genette.

Comparando-se os modos de realização da leitura de textos em diversos meios, o paratexto exerce no livro impresso uma função semelhante à dos hipertextos na internet. A diferença reside no fato de que os hipertextos redirecionam o leitor a um contexto de abertura virtual, ao passo que o livro, ao lançar mão das ferramentas de paratexto, possui a propriedade de apresentar e abarcar seus dados informativos em si, como ocorre, por exemplo, com a presença das notas de rodapé.

As notas de rodapé são compostas por observações úteis ao entendimento de um texto, apresentando-se, geralmente, de modo conciso e ao pé da página, limitadas por uma linha, ou ao final da publicação. Entre os seus objetivos, visam apontar as fontes de citações, incluir indicações bibliográficas de apoio e dados complementares ao texto principal, bem como expor um posicionamento ou uma contextualização acerca de visões trazidas pelo texto. Representam pausas intercaladas à leitura corrente.

No atual contexto profissional da área da tradução observa-se, tendencialmente, uma redução das notas de rodapé nas obras traduzidas sob diversas justificativas, como, por exemplo, o prejuízo na fluência da leitura da obra, a busca por uma diagramação mais simplificada das páginas e a possibilidade de eleição de critérios de traduzibilidade que minimizem a necessidade de informações adicionais e aproximem de modo otimizado as línguas e as culturas envolvidas no processo tradutório. No entanto, embora esses fatores sejam de importante observação, as notas de rodapé continuam a se apresentar nos livros, mesmo que em menor volume, e possuem aplicações funcionais nos processos de composição textual.

O tradutor italiano Pasquale Aniel Jannini (1921 - 1988), do qual algumas notas de rodapé serão observadas adiante, foi também professor de língua e literatura francesa na Università La Sapienza di Roma e um acadêmico interessado por literatura internacional, tendo dedicado parte de sua carreira à tradução e ao estudo da literatura em língua portuguesa de Portugal e do Brasil. Em 1961 publicou Orfeo Negro na Itália, tradução de Orfeu da Conceição, de Vinicius de Moraes, em italiano. A obra original, escrita em português brasileiro e publicada no Brasil em 1956 com o subtítulo "Tragédia Carioca”, alcançou sucesso expressivo no âmbito literário, teatral e cinematográfico. Destaca-se pela reinvenção do mito de Orfeu no cenário dos morros do Rio de Janeiro entre as décadas de 1950 e 1960.

No prefácio de Orfeo Negro, Emilio Mariano (diretor da coleção literária da qual a obra faz parte) revela alguns dos objetivos editoriais para a tradução em italiano de Orfeu da Conceição. 
A escolha de Orfeu da Conceição para compor a coleção deveu-se ao sucesso do filme Orfeu Negro, que popularizou internacionalmente a trama escrita por Vinicius de Moraes para o teatro. O diretor entendeu que tornar conhecido na Itália o texto que originara essa premiada produção cinematográfica ítalo-franco-brasileira seria um modo de oferecer um conhecimento oportuno e relevante ao público leitor italiano. Segundo o diretor, Vinicius de Moraes teve o mérito de transportar o mito de Orfeu para a realidade brasileira de forma simples e plausível, sem intelectualismos, e de acordo com os moldes da poesia e da música. Por esse motivo, em consenso com o editor, concebeu que o texto da obra Orfeu da Conceição - sem desconsiderar a especificidade de sua ligação com o teatro - deveria ter lugar na coleção literária "Il Mosaico dei Poeti” através da tradução Orfeo Negro. Algumas notas de rodapé de Jannini, presentes nessa tradução, serão observadas de acordo com conceitos de Lawrence Venuti (VENUTI, 1999), tradutor e teórico dos Estudos da Tradução.

Venuti definiu uma nomenclatura para língua estrangeira e língua doméstica: língua de partida e língua de chegada, respectivamente. De acordo com essa classificação, o autor buscou determinar algumas distinções entre tradução domesticadora e estrangeirizadora. A tradução domesticadora busca equilibrar as diferenças linguísticas e extralinguísticas entre o texto-fonte e o texto-meta, realizando a domesticação do texto ao promover a substituição dos elementos linguísticos e culturais da língua estrangeira por aqueles da língua de chegada. A tradução estrangeirizadora, por sua vez, é a prática tradutória que mantém as características linguísticas e culturais do texto estrangeiro no texto traduzido - não somente por meio de escolhas lexicais, mas sob o ponto de vista cultural, sociológico, histórico ou até mesmo pela manutenção de estruturas sintáticas do texto estrangeiro, sendo que as expressões e idiomatismos são inseridos na tradução com o escopo de gerar no leitor impressões similares àquelas do texto original. $\mathrm{O}$ principal objetivo, nesse caso, é conservar o efeito do que é "estrangeiro", deixando claro ao leitor de que se trata de um texto traduzido na língua em que se está realizando a leitura. Tal mecanismo tradutório sugere que "a literatura traduzida pode ter um papel importante na visão de mundo ao dar aos cidadãos a sensação de familiaridade com coisas estrangeiras" (MILTON, 2002), levando os leitores estrangeiros a elaborarem suas visões particulares e a efetuarem suas próprias correlações e aproximações entre o contexto em que se situam e aquele retratado na obra traduzida.

Para estabelecer os conceitos de domesticação e estrangeirização, Venuti tomou como base a dimensão discursiva integral de uma tradução. $\mathrm{O}$ autor evidencia que as ideologias envolvidas 
na determinação do processo tradutório, bem como a atividade em si, definem se a tradução será considerada mais domesticadora ou estrangeirizadora. Infere também que, independentemente de tais ideologias ou da metodologia adotada, todo texto original que passa pelo processo de tradução receberá elementos da língua e cultura domésticas.

Em Orfeo Negro, Jannini parece mesclar tendências domesticadoras e estrangeirizadoras na tradução. Observa-se ao longo da obra, por exemplo, a presença de notas de rodapé nas quais o tradutor busca expor - pelo que o texto denota, especialmente ao leitor de nacionalidade italiana - conceitos relacionados à língua e cultura brasileiras. Dessa forma, efetua uma operação estrangeirizante, como pode-se observar a seguir nos casos selecionados (dentre outros presentes no livro):

\begin{tabular}{|c|c|c|}
\hline $\begin{array}{c}\text { Referência em } \\
\text { Orfeu da Conceição }{ }^{I}\end{array}$ & $\begin{array}{c}\text { Referência em } \\
\text { Orfeo Negro }\end{array}$ & $\begin{array}{l}\text { Nota de Rodapé em } \\
\text { Orfeo Negro }\end{array}$ \\
\hline $\begin{array}{l}\text { "Poucos segundos depois, } \\
\text { aparece Orfeu acompanhando } \\
\text { no violão um choro que se } \\
\text { executa longe no morro." }\end{array}$ & $\begin{array}{l}\text { "Pochi secondi più tardi, appare } \\
\text { Orfeo che accompagna sulla } \\
\text { chitarra un }<<\text { chôro }>>1 \text { che } \\
\text { viene eseguito lontano, sulla } \\
\text { collina." }\end{array}$ & $\begin{array}{l}\text { “ I Chôro: composizione } \\
\text { musicale tipica del Brasile, } \\
\text { eseguita da un piccolo complesso } \\
\text { strumentale composto di flauto, } \\
\text { chitarra, cavaquinho (strumento } \\
\text { a quattro corde), pandeiro } \\
\text { (specie di tamburello) e reco- } \\
\text { reco (strumento a percussione } \\
\text { che produce un suono di raspa } \\
\text { causato dall'attrito di due parti } \\
\text { distinte)." }\end{array}$ \\
\hline $\begin{array}{l}\text { "Ciranda, cirandinha } \\
\text { Vamos todos cirandar } \\
\text { Já bateu a meia noite } \\
\text { Carnaval vai acabar." }\end{array}$ & $\begin{array}{l}\text { "Ciranda Cirandinhal } \\
\text { Balliamo la ciranda } \\
\grave{E} \text { venuta mezzanotte } \\
\text { Carnevale sta finendo" }\end{array}$ & $\begin{array}{l}\text { " }{ }^{1} \text { Ciranda: danza popolare } \\
\text { brasiliana, chiamata anche } \\
<<\text { cirandinha }>>\text {." }\end{array}$ \\
\hline
\end{tabular}

1 MORAES, Vinícius de. Orfeu da Conceição (1 ${ }^{\mathrm{a}}$ ed.). Rio de Janeiro: Imprensa Nacional, 1956. (pp. 50, 79 e 105) 2 MORAES, Vinícius de. Orfeo Negro. Trad. Pasquale Aniel Jannini. Milano: Nuova Accademia Editrice, 1961. (pp. 70,100 e 127)

3 Idem 2 
Efetuando tais correspondências entre as culturas brasileira e italiana, Jannini age na tradução conforme a observação de Venuti acerca do tratamento de determinadas informações estrangeirizantes, em que "L'estraneità nella traduzione estraniante è segnalata più decisamente dall'associazione del familiare e del meno familiare sulle scene domestiche" (VENUTI, 1999, p. III). ${ }^{4}$

Em contrapartida, ao promover também determinadas escolhas tradutórias domesticadoras, o tradutor sugere a busca por aproximações da cultura brasileira com a cultura italiana, a fim de, provavelmente, reduzir a distância entre o texto de partida e o leitor final, utilizando elementos próprios da cultura do texto de chegada.

Como exemplo, podemos citar a associação de cantigas infantis na tradução - a versão brasileira de "Escravos de Jó" à versão de uma cantiga chamada "Girotondo" em italiano, ambas de raízes populares - que pode-se observar abaixo. As cantigas não apresentam necessariamente o mesmo conteúdo e procedência, mas frequentemente fazem parte do imaginário cultural e de brincadeiras parecidas entre crianças com a mesma faixa etária no Brasil e na Itália.

\begin{tabular}{|c|c|c|}
\hline $\begin{array}{c}\text { Referência em } \\
\text { Orfeu da Conceiçâa } o^{5}\end{array}$ & $\begin{array}{c}\text { Referência em } \\
\text { Orfeo Negro }^{6}\end{array}$ & $\begin{array}{l}\text { Nota de Rodapé em } \\
\text { Orfeo Negro }\end{array}$ \\
\hline $\begin{array}{l}\text { "Os escravos de Job } \\
\text { Gostavam de brigar } \\
\text { Vira, mata, pega o zamberê } \\
\text { Que dá! } \\
\text { Guerreiro com guerreiro } \\
\text { (bis) } \\
\text { Zip-zip-zip-zá! } \\
\text { (bis)" }\end{array}$ & $\begin{array}{l}\text { "Gli schiavi di Giobbe } \\
\text { Amavan litigare } \\
\text { Gira, uccidi, piglia il zamberé } \\
\text { Dai dai dai! } \\
\text { Guerriero con guerriero } \\
\text { Guerriero con guerriero } \\
\text { Zip-zip-zip-zá! } \\
\text { Zip-zip-zip-zá! " " }\end{array}$ & $\begin{array}{l}\text { " } 2 \text { Si tratta di una cantilena } \\
\text { infantile equivalente al } \\
<<\text { Girotondo }>>\text { italiano." }\end{array}$ \\
\hline
\end{tabular}

4 A estranheza na tradução estrangeirizante é marcada incisivamente pela associação do familiar e do menos familiar em cenas domésticas. (tradução minha)

5 MORAES, Vinícius de. Orfeu da Conceição (1 ${ }^{\mathrm{a}}$ ed.). Rio de Janeiro: Imprensa Nacional, 1956. (pp. 50, 79 e 105) 6 MORAES, Vinícius de. Orfeo Negro. Trad. Pasquale Aniel Jannini. Milano: Nuova Accademia Editrice, 1961. (pp. 70,100 e 127)

7 Idem 6 
De acordo com Venuti, a abordagem tradutória domesticadora ou estrangeirizadora deve ser escolhida conforme as intenções do tradutor (que, por sua vez, considera também as determinações editoriais) em relação ao texto de origem.

Dessa forma, o autor explica que se o texto de partida estiver inserido em um sistema linguístico e cultural periférico, como é o caso de Orfeu da Conceição, pode-se desenvolver um projeto tradutório que destaque os aspectos dessa cultura, sendo este procedimento classificado como um projeto minorizante - conforme pode ser entendido o trabalho realizado por Jannini em Orfeo Negro.

\section{Referências}

GENETTE, Gérard. Paratextos editoriais. Tradução de Álvaro Faleiros. São Paulo: Ateliê Editorial, 2009.

MILTON, John. O clube do livro e a tradução. Bauru: Editora da Universidade do Sagrado Coração (EDUSC), 2002.

MORAES, Vinícius de. Orfeu da Conceição (1ª ed.). Rio de Janeiro: Imprensa Nacional, 1956.

MORAES, Vinícius de. Orfeo Negro. Trad. Pasquale Aniel Jannini. Milano: Nuova Accademia Editrice, 1961.

VENUTI, Lawrence. L'invisibilità del traduttore. Roma: Armando Editore, 1999.

VENUTI, Lawrence. Escândalos da tradução: por uma ética da diferença. Tradução de Valéria Biondo et al. Bauru: Editora da Universidade do Sagrado Coração (EDUSC), 2002.

Recebido em 14/12/2016

Aprovado em 14/04/2017 